\title{
The Effect of Prenatal Ultrasound Heating Throughout Gestation on Rabbit Fetal Weight
}

\author{
F. W. A. Zaiki ${ }^{1}$ and S. M. Dom ${ }^{1}$ \\ ${ }^{1}$ Faculty of Health Sciences, Universiti Teknologi MARA, 42300 Puncak Alam, \\ Selangor, Malaysia. \\ farahzaiki@yahoo.com
}

\begin{abstract}
The aim of this in vivo experimental study is to determine the association between ultrasound exposure time and rabbit fetal weight. A total of 14 pregnant does were exposed to ultrasound heating for 30, 60, and 90 minutes of ultrasound exposure at their middle of each gestational stage, while another 4 pregnant does served as control. Total of 136 fetuses $\left(1^{\text {st }}\right.$ stage, $n=34(25 \%) ; 2^{\text {nd }}$ stage, $n=28(20.6 \%) ; 3^{\text {rd }}$ stage, $\left.n=74(54.4 \%)\right)$ were analyzed for fetal body weight. There were significant differences in fetal weight at all stages $(p<0.05$; 95\% CI do not cross 0 ) of all groups at different length of exposure time. There were also negative correlation between groups with different exposure durations and fetal weight in the $1^{\text {st }}$ and the $3^{\text {rd }}$ stage ( $p<0.05 ; r=-0.40, p<0.05 ; r=-0.23$ respectively). Exposure time was found poorly associated with fetal weight in the $1^{\text {st }}$ and the $3^{\text {rd }}$ stage $\left(p<0.05 ; r^{2}=0.15\right.$ and 0.04 respectively). This study suggests the heating effect of ultrasound exposure might act as a noxious agent that promotes intrauterine growth restriction in developing fetus that might consequently impacts the rabbit fetal weight. Therefore a considerably increase in awareness of negligible effects aroused from prenatal ultrasound exposure was concerned as it was widely applied to pregnant women.
\end{abstract}

Keywords: Fetal weight, gestation, prenatal, ultrasound heating

\section{Introduction}

Ultrasound is widely accepted in clinical practice, where it has been found to reduce perinatal mortality due to its ability in early detection of fetal malformations [1]. Prenatal ultrasound has four basic usage, namely; assessment of normality or abnormality of the $1^{\text {st }}$ trimester, assessment of gestational age approximately implemented below 22 weeks of gestation $\left(2^{\text {nd }}\right.$ trimester) and fetal number such as in multiple pregnancy, assessment of structural abnormalities and assessment of growth and fetal well-being throughout pregnancy [2]. Fetal abnormalities are usually detected earlier in pregnancy while fetal growth become a major factor in fetal size estimation later in pregnancy $[2,3]$.

Earlier scan which is typically done during less than 15 weeks of gestation is also called a dating measurements scan where the gestational age and estimated date of delivery (EDD) are determined [4-6]. The measurements that are taken into account in establishing the gestational age and Estimated Fetal Weight (EFW) includes the bi-parietal diameter (BPD), head circumference (HC), abdominal circumference (AC) and femur length (FL) [2, 5, 7-10]. The $1^{\text {st }}$ trimester scan is ideal in detection of fetal anomalies such as aneuploidy. This is based on the measurement of nuchal translucency (NT), an antero-posterior measurement of fluid distance over fetal head and neck $[5,8,11]$. 
The $2^{\text {nd }}$ trimester scan in detection of major fetal abnormalities is also called anomaly scan, routinely performed between 18 and 20 weeks of gestation to detect fetal structural abnormalities $[5,12,13]$. Fetal growth retardation or intrauterine growth restriction (IUGR) occurred when fetal growth is in the lesser $5^{\text {th }}$ percentiles of birth weight. It can be divided into type 1 and type 2 , which can occur during $2^{\text {nd }}$ and $3^{\text {rd }}$ trimester of pregnancy respectively. This condition is detected when there is an asymmetrical growth indicated by elevated HC and $\mathrm{AC}$ ratio from prenatal ultrasound scan. In addition, early detection of IUGR can also be confirmed via amniocentesis or biopsy [2]. Therefore, identification of suspected IUGR should occur before birth through a prenatal ultrasound scan at a late stage of pregnancy. In the official statements made by the American Institute of Ultrasound in Medicine (AIUM), the institute advocates the prudent use of prenatal ultrasound and it should be strongly restricted for nonmedical usage as such for entertainment purposes including fetal viewing, obtaining fetal images or even fetal gender screening without clinical indications [14].

As an ultrasound wave propagates through the human body, it interacts with the human anatomy, therefore creating diagnostic images. However, throughout the process, it is being attenuated, reflected, scattered and also absorbed by human body as heat. A large body of literature have investigated and reviewed the embryos of many mammals and found it to be susceptible to heat damage. Embryonic development consists of highly ordered sequences of cell proliferation, cell differentiation, cell migration and apoptosis (programmed cell death). If the process are interfered by the presence of heat, they are prone to incidence of craniofacial defects and microencephaly in animals. It was also reported that the embryo in $1^{\text {st }}$ trimester consists of actively dividing tissue and is more susceptible than mature tissue to damages caused by any external agent $[15,16]$ including physical injuries by ultrasound heating [17].Their sensitivity are somehow dependent on the stages of gestation [18]. In fact, hyperthermia has been recognized as a teratogen in animals in numerous studies, therefore, it is logical to suspect that the same teratogenicity effect could occur in humans as well [19]. As the safety issues of ultrasound are still debatable, hence, this study is designed to assess whether there is an association or relation between ultrasound exposure time and rabbit fetal weight during $1^{\text {st }}, 2^{\text {nd }}$ and $3^{\text {rd }}$ stage of pregnancy.

\section{Methods}

The research was carried out in Animal Handling Research Laboratory, Universiti Teknologi MARA (UiTM), Puncak Alam Campus. The ethical approval was obtained from Committee on Animal Research and Ethics (UiTM CARE) before the experiment was carried out.

\subsection{Animals}

To evaluate the bio-effect of ultrasound heating to rabbit fetal weight, the following experiments were carried out. This in-vivo experimental study involved the use of 18 female New Zealand White rabbits (Oryctolagus cuniculus). 4 does (female rabbit) served as controlled group while the rest were categorized as treated group.

The courtship and mating sessions of does were arranged systematically with the ratio of being three female to one male. The does' egg will be fertilized about an hour and a half after release of ovocytes. Ovulation is normally stimulated by coitus and normally occurs 10-12 hours after mating [20]. Due to these characteristics of accurately timed ovulation and fertilization of the rabbit, the first day of conception and the middle of each stage can be correctly determined. All pregnant does were treated equally while every external factors were kept constant (Surrounding temperature: $28^{\circ} \mathrm{C}$, humidity: 60-65\%). The does were 
housed individually in 18 separate cages with dimension of $76.2 \mathrm{~cm}$ x $50.8 \mathrm{~cm}$ x $60.7 \mathrm{~cm}$ and given ad libitum access to standard laboratory chow and filtered tap water. Good ventilation was ensured by using BioGS air purifier, from RabbitAir, USA to expel harmful gases released by rabbits such as $\mathrm{CO}_{2}$ (Carbon dioxide) and $\mathrm{NH}_{3}$ (Ammonia) [20, 21]. This was critical to prevent incidental confounding factor that might affect the validity of subjects since the goal was to access the heating effect of ultrasound to a fetus in a womb.

\subsection{Ultrasound Exposures}

Ultrasound exposures of 30 minutes, 60 minutes and 90 minutes were used as a teratogen, and were given prenatally to pregnant does at the middle of each gestational stage. The exposures were carried out during gestational day (GD) 6-7, GD 17-18 and GD 28-29 for $1^{\text {st }}$, $2^{\text {nd }}$ and $3^{\text {rd }}$ stage of pregnancy respectively after dividing the normal gestational period of a rabbit into three stages to imitate trimesters in human pregnancy. Gestational period of rabbit usually varies between 31-33 days [22]. For control group, no ultrasound exposure was given. This study used Philips HD3 ultrasound machine from Koninklijke Philips N.V, Netherlands 2D operating at B-mode pulsed-ultrasound. With an exception of the lengths of exposure time (eg: 30, 60, 90 minutes), ultrasound parameters such as transducer frequency, thermal index (TI) and mechanical index (MI) were kept constant. Transducer of linear array, L 5-9 with the ability to transmit frequency between $5 \mathrm{MHz}$ until $9 \mathrm{MHz}$ was used. Focal distance was kept constant at $4.5 \mathrm{~cm}$ throughout the experiments. The TI and MI displayed by the output display throughout the experiment showed the value of 0.2 and 1.0 respectively. The output power and intensities, (I SPTA) (spatial peak temporal average intensity) of ultrasound varies from 0.4 $\mathrm{W}$ to $0.7 \mathrm{~W}$ and 0.13 to $0.19 \mathrm{~W} / \mathrm{cm}^{2}$ respectively when measured in water for the durations of 30, 60 and 90 minutes of ultrasound exposures. The parameter of interest were usually determined in free-field experimental conditions where there were without reflectors or other disturbances to an ultrasonic field [23]. When soft tissue replaced water along the ultrasonic pathways in researcher's real experiment involving animal subject as a model, rabbit, a decrease in intensity was expected, because soft tissue had a much higher rate of attenuation as compared to water[3, 24].

All pregnant does were sacrificed 48 hours after ultrasound exposure. Pregnant does were euthanized using Pentobarbital sodium, Doléthal 250ml from Ethical Agents Ltd. NZ, $1 \mathrm{ml} / \mathrm{kg}$ body weight by intravenous injection or $0.75 \mathrm{ml} / \mathrm{kg}$ intra-cardiac injection. Fetuses were taken out and fetal body weight was measured. A total of 136 fetuses $\left(1^{\text {st }}\right.$ stage, $n=34 ; 2^{\text {nd }}$ stage, $n=28 ; 3^{\text {rd }}$ stage, $n=74$ ) were analyzed for fetal body weight using calibrated A \& D Ek610i digital scale weighing balance from A \& D Corporation, USA. An average of three readings were recorded. Statistical Package for the Social Sciences, SPSS version 21.0 was used to analyze the data, to make inference and draw robust conclusions.

\section{Results}

The data were expressed as means \pm standard deviation (SD) in a descriptive statistic that were initially done to evaluate the distribution, normality and homogeneity of the data. Table 1 showed the fetal weight characteristics of 136 fetuses throughout the gestational stages. The calculated mean showed the declined of fetal weight at all stages $\left(1^{\text {st }}, 2^{\text {nd }}\right.$ and $3^{\text {rd }}$ stage $)$ as the exposure durations was increased. Fig. 1-3 displayed the mean fetal weight plotted in graphical view for the $1^{\text {st }}, 2^{\text {nd }}$ and $3^{\text {rd }}$ stage respectively. The mean fetal weight at $1^{\text {st }}, 2^{\text {nd }}$ and $3^{\text {rd }}$ stage were documented lowest in 90 minutes exposure group. Among all gestations, the $2^{\text {nd }}$ and the $3^{\text {rd }}$ stage mean of fetal weight were peaked at 60 minutes of ultrasound exposure 
while being flattened during 30 and 60 minutes of exposure for $1^{\text {st }}$ stage group before fell to their lowest values at 90 minutes of exposure.

Statistical analyses that were carried out simultaneously to compare the mean between groups includes one-way analysis of variance (ANOVA) for groups with normal distribution while the Kruskal-Wallis analysis of variance for groups with non-normal distribution where $\mathrm{P}$ value $<0.05$ was considered significant. Statistical tests of fetal weight in each gestation between different exposure durations were shown in table 2. P-values are $0.00(\mathrm{p}<0.05)$ in the $1^{\text {st }}, 2^{\text {nd }}$ and $3^{\text {rd }}$ stage (all gestations). The 95\% confident intervals (CI) for all gestations are also do not cross 0 . The results suggest that there are significant differences in fetal weight at all stages $\left(1^{\text {st }}, 2^{\text {nd }}\right.$ and $3^{\text {rd }}$ stage $)$ of all groups with different exposure durations. Further statistical analyses to detect any association between fetal weight and different exposure durations, the Pearson correlation and Spearman's rank order correlation shows negative correlation between different exposure durations and fetal weight at the $1^{\text {st }}$ and the $3^{\text {rd }}$ stage $(\mathrm{p}<0.05$ and $\mathrm{r}=-0.40, \mathrm{p}<0.05$ and $\mathrm{r}=-0.23$ respectively). Therefore, longer ultrasound exposure time is associated with lower fetal weight specifically for fetus at the $1^{\text {st }}$ and the $3^{\text {rd }}$ stage. There are also significant linear relationship between the exposure durations and fetal weight at the $1^{\text {st }}$ and the $3^{\text {rd }}$ stage $(p<0.05)$. Regression coefficient, $r^{2}$, are 0.15 and 0.04 respectively, indicating poor relationship between the exposure durations and fetal weight. Across the exposure durations, there are variations of $15 \%$ and $4 \%$ in fetus weight at the $1^{\text {st }}$ and the $3^{\text {rd }}$ stage respectively. However, there is no significant correlation and relationship between the exposure durations and fetal weight at $2^{\text {nd }}$ stage of pregnancy $\left(\mathrm{p}>0.05, \mathrm{r}=0.10, \mathrm{r}^{2}\right.$ $=0.00)$.

Table 1. Fetal Weight Characteristics Throughout the Gestational Stages

\begin{tabular}{llccc}
\hline Gestational stage & Group & n & Mean fetal weight $(\mathbf{g})$ & SD $( \pm)$ \\
\hline $1^{\text {st }}$ stage & No exposure & 9 & 0.30 & 0.05 \\
& 30 min exposure & 6 & 0.33 & 0.05 \\
& 60 min exposure & 10 & 0.33 & 0.05 \\
& 90 min exposure & 9 & 0.21 & 0.03 \\
$2^{\text {nd }}$ stage & No exposure & 6 & 2.55 & 0.05 \\
& 30 min exposure & 10 & 2.62 & 0.18 \\
& 60 min exposure & 5 & 2.84 & 0.05 \\
& 90 min exposure & 7 & 2.53 & 0.11 \\
$3^{\text {rd }}$ stage & No exposure & 16 & 52.67 & 7.60 \\
& 30 min exposure & 19 & 51.93 & 11.06 \\
& 60 min exposure & 16 & 56.07 & 5.43 \\
TOTAL & 90 min exposure & 23 & 46.44 & 6.94 \\
\hline
\end{tabular}




\section{Table 2. Statistical Tests of Fetal Weight in Each Gestational Stage between Groups of Different Exposure Durations}

\begin{tabular}{|c|c|c|c|c|c|}
\hline Gestational stage & Group & $95 \% \mathrm{CI}$ & P-value $^{a}$ & P-value $(r)^{b}$ & P-value $\left(r^{2}\right)^{c}$ \\
\hline \multirow[t]{4}{*}{$1^{\text {st }}$ stage } & No exposure & 0.26 to 0.34 & $0.00 *$ & $0.02 *(-0.40)$ & $0.02 *(0.15)$ \\
\hline & $30 \mathrm{~min}$ exposure & 0.28 to 2.55 & & & \\
\hline & $60 \mathrm{~min}$ exposure & 0.30 to 0.37 & & & \\
\hline & 90 min exposure & 0.15 to 0.27 & & & \\
\hline \multirow[t]{4}{*}{$2^{\text {nd }}$ stage } & No exposure & 2.49 to 2.61 & $0.01 *$ & $0.60(0.10)$ & $0.82(0.00)$ \\
\hline & $30 \mathrm{~min}$ exposure & 2.49 to 2.75 & & & \\
\hline & $60 \mathrm{~min}$ exposure & 2.77 to 2.91 & & & \\
\hline & $90 \mathrm{~min}$ exposure & 2.43 to 2.63 & & & \\
\hline \multirow[t]{4}{*}{$3^{\text {rd }}$ stage } & No exposure & 48.62 to 56.72 & $0.00 *$ & $0.04 *(-0.23)$ & $0.04 *(0.04)$ \\
\hline & $30 \mathrm{~min}$ exposure & 46.60 to 57.26 & & & \\
\hline & $60 \mathrm{~min}$ exposure & 53.18 to 58.96 & & & \\
\hline & $90 \mathrm{~min}$ exposure & 43.44 to 49.44 & & & \\
\hline
\end{tabular}

${ }^{\mathrm{a}}$ ANOVA ; ${ }^{\mathrm{b}}$ Correlation test ; ${ }^{\mathrm{C}}$ Prediction test

${ }^{*} p<0.05$; statistical tests were performed by a parametric or a non-parametric test

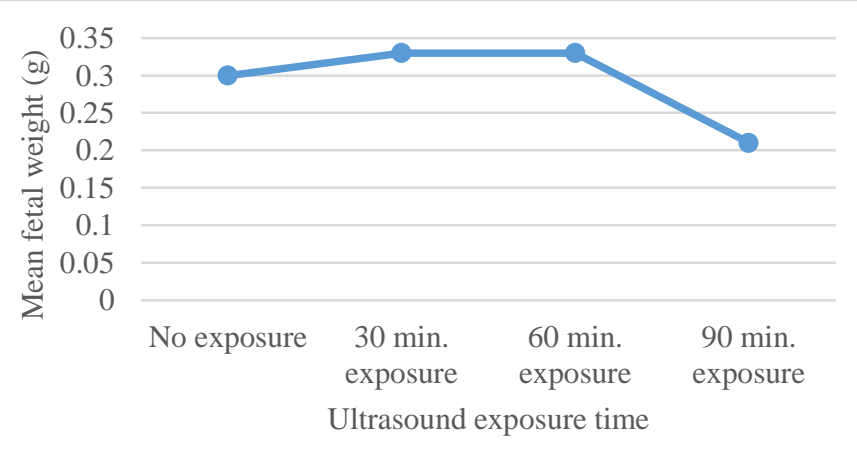

Figure 1. The $1^{\text {st }}$ Stage Mean Fetal Weight in Groups of Different Exposure Durations

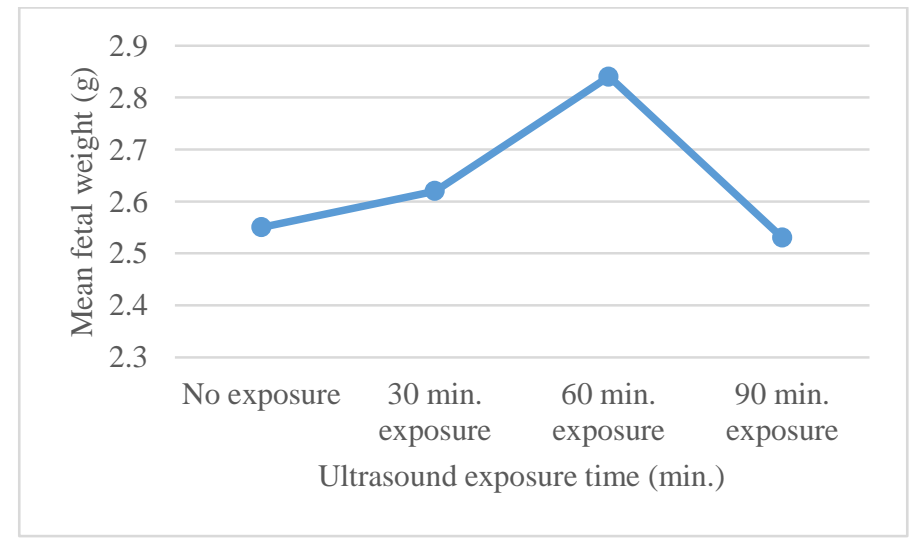

Figure 2. The $2^{\text {nd }}$ Stage Mean Fetal Weight in Groups of Different Exposure Durations 


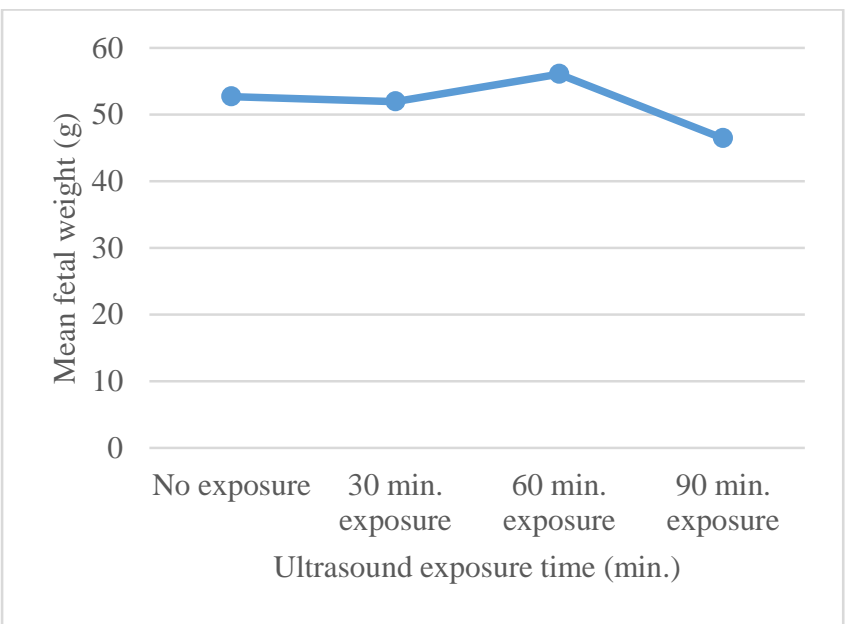

Figure 3. The 3rd Stage Mean Fetal Weight in Groups of Different Exposure Durations

\section{Discussion}

The findings in this study showed that the fetal weight at all gestational stages, the $1^{\text {st }}, 2^{\text {nd }}$ and $3^{\text {rd }}$ stage were statistically significant among ultrasound exposed and non-exposed group. In prenatal development, the sensitivity to a teratogen, heat, varies between gestational stages, the state of maturation of the structures and also varies considerably between species. A major developmental period in rabbit includes pre-implantation stage (GD 0-5) where there is fertilization and implantation of embryo into uterine wall; organogenesis stage (GD 6-15), is when the formation of major body structures; and finally a fetal stage (GD 16-31.5) where there is growth of the structures [18].

Throughout these 3 stages $\left(1^{\text {st }} 2^{\text {nd }}\right.$ and $3^{\text {rd }}$ stage $)$, present research had found the differences in fetal weight among ultrasound exposed and non-exposed group. Furthermore, when the exposure durations was increased, a decrease in fetal weight was noted. Fig 1-3 showed that the mean fetal weight at the $1^{\text {st }}, 2^{\text {nd }}$ and $3^{\text {rd }}$ stage were documented lowest in 90 minutes exposure group. This indicates the possibility of ultrasound heating in causing defect in studied animal. The decreased in fetal weight at longest ultrasound exposure time groups suggests the heating effect of ultrasound exposure may act as a noxious agent that promotes IUGR in developing fetus.

In a randomized controlled trial study done by Newnham and Evans [25] found that increased frequency of ultrasound exposure and Doppler flow imaging during 18 to 38 weeks of gestation in pregnant women $\left(2^{\text {nd }}\right.$ and $3^{\text {rd }}$ trimester $)$ elevates about one third of IUGR in developing fetus as compared to single ultrasound exposure. Another study also reported that ultrasound exposure in utero could potentially cause hematopoiesis and reduced body weight in macaque (monkey) offspring [26]. Meanwhile, Bukowski et al. [27] and Smith et al. [28] reported that routine ultrasound measurement that shows small fetal size at early pregnancy is indicative of reduced birth weight. This indicated that fetus is at risk of poor growth. Moreover the IUGR had found to be prominent even at very early of pregnancy [28].

Likely the same condition is also evident in this present study where results showed an association of the $1^{\text {st }}$ and the $3^{\text {rd }}$ stage fetal weight upon an exposure to ultrasound heating in rabbit. During the $1^{\text {st }}$ trimester of pregnancy, mainly embryonic developments occur whereas the $3^{\text {rd }}$ trimester of pregnancy involves the growth of a fetus. Once the embryonic developmental period had been altered by means of ultrasound heating, it can cause growth 
restriction later in pregnancy. In utero fetus had almost no capability to regulate its own temperature and it dissipated heat by means of amniotic fluid to uterine wall and via umbilical arterial blood blow to placenta [29].

Elevated maternal temperatures, hyperthermia, could result in reduced growth, or even worse, might lead to embryonic and fetal death. An occluded umbilical cord might allow the fetal temperature to increase since there are no ways of heat exchange to occur. Therefore, a decreased in blood flow to placenta and fetus is believed to cause embryonic and fetal growth retardation [18]. Suboptimal environment in $1^{\text {st }}$ trimester of pregnancy restricted the fetal growth for the rest of pregnancy. This might be due to a placentation disorder resulting from suboptimal nutrients transferred to a fetus [28]. In another in vivo study by Dom et al. [30] the differences in fetal parathyroid hormone level in ultrasound exposed and non-ultrasound exposed group could lead to a possible result in alteration of physiological developments of fetus. This will cause various physiological variables alteration, not limited to reduction in fetal weight which was reveled in this study.

\section{Conclusion}

This fundamental in vivo experimental study suggests that the heating effect of ultrasound exposure might be related to disturbance in the physiology of studied animal, rabbit. Therefore, there should be a rising concern in the awareness towards the negligible effects produced from prenatal ultrasound exposure as it is widely applied during pregnancy in humans. Although in vivo experiments conducted in animal cannot ethically be replicated in humans, the role of fetuses in intrauterine environments in animal model is estimated to mimic the gestational stage of human pregnancy [10]. The results, when applied onto human, will therefore ensure that pregnant women will receive professional care and consultation to undergo prenatal ultrasound during pregnancy, which will also bring out medical benefits higher than that of risk while at the same time contributes to the health of the next generation of human capital.

\section{Acknowledgement}

The author would like to acknowledge the Research Management Institute (RMI) of Universiti Teknologi MARA, Shah Alam, Malaysia for the Research Intensive Faculty (RIF) grant awarded (600-RMI/DANA 5/3/RIF(229/2012). The two editors of this paper, Dr. Hairil Rasmizal Abdul Razak and Dr Hamzah Fansuri Hassan from Faculty of Health Sciences, Universiti Teknologi MARA, Puncak Alam Campus, Malaysia. The hardworking research project team members, Ms. Nurul Hidayah Saat and Ms. Khairunnisa Abdul Manan contribution towards this project. This paper is a revised and expanded version of a paper entitled, Prenatal Ultrasound Heating Influences on Fetal Weight Assessment of Oryctolagus cuniculus throughout Pregnancy, presented at Second International Workshop on Bioscience and Medical Research 2013, Jeju Island, Korea, December 11-13, 2013.

\section{References}

[1] A. Saari-Kemppainen , O. Karjalainen, P. Ylöstalo , and O. P. Heinonen., "Ultrasound Screening and Perinatal Mortality: Controlled Trial of Systematic One-Stage Screening in Pregnancy. The Helsinki Ultrasound Trial.", Lancet, vol. 336, (1990), pp. 387-91.

[2] J. McHugo, "Obstetric and Gynecology Ultrasonography," in Aids to Radiological Differential Diagnosis, 3rd ed UK: W. B. Saunders, (1990), pp. 480-504.

[3] D. L. Miller, "Safety Assurance in Obstetrical Ultrasound," Seminar in Ultrasound, CT and MR (Philadelphia PA), vol. 29, (2009), pp. 156-164.

[4] "Ultrasound Baby Scan in Pregnancy", Available: https://www.nhs.uk, (2013) October 23. 
[5] P. Chudleigh, T. Marteau, K. Nocolaides, C. Rodeck, S. Russell, and P. Soothill. "Ultrasound Screening", Available: www.rcog.uk/womens-health/clinical-guidance/ultrasound-screening, (2013) October 23.

[6] M. Wilcox, J. Gardosi, M. Mongelli, C. Ray, and I. Johnson, "Birth Weight from Pregnancies Dated by Ultrasonography in Multicultural British Population", British Medical Journal, vol. 307, (1993), pp. 588-591.

[7] S. L. Johnsen, S. Rasmussen, R. Sollien, and T. Kiserud, "Fetal Age Assessment Based on Ultrasound Head Biometry and Effect of Maternal and Fetal Factors", Acta Obstetricia et Gynecologica Scandinavica, vol. 83, (2004), pp. 716-723.

[8] J. Sonek, "First Trimester Ultrasonography in Screening and Detection of Fetal Anomalies", American Journal of Medical Genetics Part C(Seminars in Medical Genetic), vol. 145C, (2007), pp. 45-61.

[9] I. Burd, S. Srinivas, E. Pare, V. Dharan, and E. Wang, "Is Sonographic Assessment of Fetal Weight Influenced by Formula Selection?", Journal of Ultrasound in Medicine, vol. 28, (2009), pp. 1019-1024.

[10] J. Zhang, R. Sundaram, W. Sun, and J. Troendle, "Fetal Growth and Timing of Parturition in Humans", American Journal of Epidemiology, vol. 168, (2008), pp. 946-951.

[11] H. Cuckle, P.Benn, and D. Wright, "Down syndrom screening in the first and or second trimester : model predicted performance using meta-analysis parameters", Seminar in Perinatology, vol. 29, (2005), pp. 252257.

[12] "Ultrasound Scan- Fetal Growth Scan," M. M. Hospital, Ed., ed. Brisbane, (2013).

[13] M. Pahuja, "18-20 Week Screening Pregnancy Ultrasound. Available: www.insideradiolgy.com.au, (2013)

[14] "Official Statements: Prudent Use in Pregnancy", A. I. U. M. (AIUM), (2012).

[15] J. S. Abramovicz, G. Kossoff, K. Marsal, and G. T. Haar, "Safety Statement, 2000 International Society of Ultrasound in Obstetrics and Gynecology (ISUOG)", Ultrasound Obstetrics and Gynecology, vol. 16, (2000), pp. 594-596.

[16] J. S. Abramowicz, G. Kossoff, K. Marsal, and G. T. Haar, "Safety Statement 2000 (reconfirmed 2003)," Ultrasound Obstetrics and Gynecology, vol. 21, (2003), p. 100.

[17] S. B. Barnett, R. Hans-Dieter, G. T. Haar, M. C. Ziskin, and K. Maeda, "Review- The Sensitivity of Biological Tissue to Ultrasound," Ultrasound in Medicine and Biology, vol. 23, no. 6, (1997), pp. 805-812.

[18] M. J. Edwards, R. D. Saunders, and K. Shiota, "Effect of Heat on Embryos and Foetuses," International Journal of Hyperthermia, vol. 19, no. 3, (2003), pp. 295-324.

[19] C. C. Church and M. W. Miller, "Review- Quantification of Risk from Fetal Exposure to Diagnostic Ultrasound," Progress in Biophysics and Molecular Biology, vol. 93, (2006), pp. 331-353.

[20] F. Lebas, P. Coudert, R. Rouvier, and H. d. Rochambeau, "The Rabbit: Husbandry, Health and Production," in Food and Agriculture Organization (FAO) Animal Product and Health Series, [Online]. Available: http://www.fao.org/docrep/X5082E/X5082E00.HTM. (2010)

[21] F. Lebas, P.Coudert, H. d. Rochambeau, and R. G. Thebault, "The Rabbit Husbandry, Health and Production", (1997).

[22] A. K. Palmer, "Spontaneous Malformations of the New Zealand White Rabbit: The Background to Safety Evaluation Tests," Laboratory Animal, vol. 2, (1968), pp. 195-206.

[23] W. R. Hedrick, D. L. Hykes, and D. E. Starchman, "Intensity and power," in Ultrasound Physics and Instrumentation, 4th ed Philadelphia, USA: Elsevier, (2005), pp. 294-300.

[24] W. R. Hedrick, D. L. Hykes, and D. E. Starchman, "Basic ultrasound physics," in Ultrasound Physics and Instrumentation, 4th ed Philadephia, USA: Elsevier, (2005), pp. 1-22.

[25] J. P. Newnham and S. F. Evans, "Effects of Frequent Ultrasound During Pregnancy: A Randomised Controlled t $\backslash$ Trial," Lancet, vol. 342, (1993), pp. 887-891.

[26] A. F. Tarantal, W. D. O'Brien, and A. G. Hendrickx, "Evaluation of Bioeffects of Prenatal Ultrasound Exposure in Cynomolgus Macaque (Macaca fascicularis):III. Developmental and Hematologic Studies", Teratology, vol. 47, (1993), pp. 159-170.

[27] R. Bukowski, G. C. Smith, F. D. Malone, R. H. Ball, D. A. Nyberg, C. H. Comstock, G. D. V. Hankins, R. L. Berkowitz, S. J. Gross, L.Dugoff, S. D. Craigo, I. E. T-Tritsch, S. R. Carr, H. M. Wolfe, and M. E. D'Alton, "Fetal Growth in Early Pregnancy and Risk of Delivering Low Birth Weight Infant: Prospective Cohort Study," British Medical Journal, (2007), pp. 1-5.

[28] G. C. Smith, M. F. Smith, M. B. McNay, and J. E. Fleming, "First-Trimester Growth and the Risk of Low Birth Weight," New England Journal of Medicine, vol. 339, (1998), pp. 1817-1822.

[29] H. J. Shroder and G. G. Power, "Engine and Radiator: Fetal and Placental Interactions for Heat Dissipation," Experimental Physiology, vol. 82, (1997), pp. 403-414.

[30] S. M. Dom, H. R. A. Razak, F. W. A. Zaiki, N. H. Saat, K. A. Manan, I. N. C. Isa, and U. F. Hashim, "Ultrasound Exposure During Pregnancy Affects Rabbit Foetal Parathyroid Hormone (PTH) Level", Quantitive Imaging in Medical and Surgery, vol. 3, (2013), pp. 49-53. 


\section{Authors}

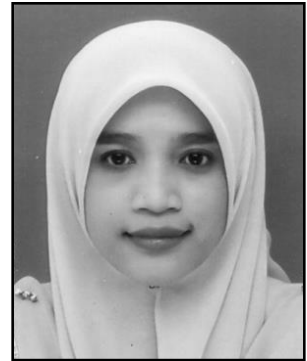

F. W. A. Zaiki is a Ph.D student and fellow at Department of Medical Imaging Faculty of Health Sciences, Universiti Teknologi MARA, Puncak Alam Campus, Selangor, MALAYSIA since 2011. She has a first class degree in Bachelor of Medical Imaging (Hons) from Universiti Teknologi MARA on 2011. Currently pursuing her doctoral degree in an in-vivo experimental research entitled Prenatal Diagnostic Ultrasound Exposure Induces Cerebral Tissue Changes in Rabbit.

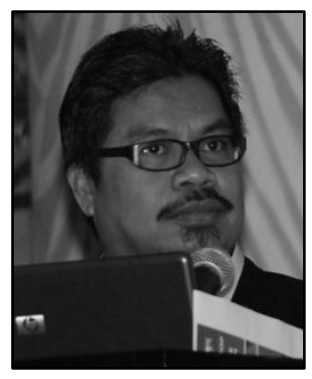

S. M. Dom is Lecturer of Department of Medical Imaging, Faculty of Health Sciences, Universiti Teknologi MARA, Puncak Alam Campus, Selangor, MALAYSIA since 1998. Previously he was a diagnostic radiographer served for the Ministry of Health Malaysia for 12 years. Currently, a senior lecturer in Ultrasound Physics \& Instrumentation and Sectional Anatomy fields for bachelor degree and master degree in Medical Imaging of UiTM. $\mathrm{He}$ is also a researcher in experimental study in Medical Imaging using rabbit. 
International Journal of Bio-Science and Bio-Technology Vol.6, No.3 (2014) 